\title{
装配式建筑结构中的叠合板施工技术探讨
}

\author{
李建萌 \\ 北京城建亚泰宏禹装饰工程有限公司，北京 100013
}

\begin{abstract}
[摘要]由于经济的飞速发展, 对建筑行业有着更高的标准, 在建筑建设阶段, 预制叠合板施工技术的合理应用有着重要意义, 施工人员要对其进行深入研究, 保证可以高效进行工程施工。文中主要介绍了装配式建筑结构中的预制叠合板施工技术, 采 用现代集合加工方法, 减少施工成本, 节省人力、物力, 提高施工质量, 坚持集中装修的原则, 预制构件按照受力特点运用 合适的连接方法和现浇结构合为一体, 加大结构承载力, 满足变形要求, 可以避免由于二次装修而产生大量建筑垃圾, 提高 施工技术的整体应用效率, 以装配式建筑结构为基础, 分析技术操作要点与相关注意事项, 现阶段的房屋建造方法为混凝土 现浇体系, 有利于城乡建设快速发展, 但缺点也较为明显, 比如建材的大量浪费、施工现场环境脏乱、开裂渗漏情况严重等, 意味着传统建设方法难以满足实际需要, 装配式建筑则能够很好解决相应问题, 预制叠合板的运用更加体现出绿色低碳理念, 实现标准化设计，工厂化生产，建造过程信息化，大幅度提高建设效率，缩短工期，增加安全系数，达到环保节能效果。
\end{abstract} [关键词]装配式建筑; 预制叠合板; 施工技术

DOI: $10.33142 / a e m . v 3 i 2.3725$ 中图分类号: TU741 文献标识码: A

\section{Discussion on Construction Technology of Laminated Plate in Prefabricated Building Structure}

\author{
LI Jianmeng
}

Beijing Chengjian Yatai Hongyu Decoration Engineering Co., Ltd., Beijing, 100013, China

\begin{abstract}
Due to the rapid development of economy, there is a higher standard for the construction industry. In the construction stage, the reasonable application of prefabricated laminated plate construction technology is of great significance and the construction personnel should conduct in-depth research on it to ensure that the engineering construction can be carried out efficiently. This paper mainly introduces the construction technology of laminated plate in prefabricated building structure. Modern collective processing method is adopted to reduce construction cost, save manpower and material resources, improve construction quality, adhere to the principle of centralized decoration and integrate prefabricated components with cast-in-place structure according to stress characteristics, so as to increase structural bearing capacity and meet deformation requirements, which can avoid a large amount of construction waste due to secondary decoration and improve the overall application efficiency of construction technology. Based on the prefabricated building structure, the technical operation points and related precautions are analyzed. The current housing construction method is concrete cast-in-place system, which is conducive to the rapid development of urban and rural construction, but the disadvantages are also obvious, such as a lot of waste of building materials, dirty construction site environment, serious cracking and leakage, which means that the traditional construction methods are difficult to meet the actual needs. Prefabricated building can well solve the corresponding problems. The application of prefabricated composite board reflects the concept of green and low carbon, realizes standardized design, industrialized production, informatization of construction process, greatly improves the construction efficiency, shortens the construction period, increases the safety factor and achieves the effect of environmental protection and energy saving.
\end{abstract}

Keywords: prefabricated building; prefabricated laminated plate; construction technology

\section{引言}

在装配式建筑施工过程中, 预制墙下端运用企口方法和下层墙板进行固定, 设置侧面预埋螺栓套筒将现浇部分和 预制墙板组成整体, 叠合组件表面上固定钢筋, 浇筑后变成整体, 让预制构件连接更为合理。构件厂商需确定截面尺 寸与位置, 在一定程度上提高平整度, 精度提高到毫米级, 有效控制产品质量。

\section{1 叠合板施工技术应用价值}

使用叠合板施工技术无需在施工现场装置并拆解楼板底模, 另外, 也不用设置底部钢筋, 使混凝土浇筑工作量大 幅度降低, 加快施工进度, 可以降低成本, 采用现代集合加工技术让人工成本大幅度减少, 在长方向对板下支撑合理 设计, 无需模板, 可以降低超过 $70 \%$ 的周转材料。要对以往楼板混凝土浇筑与钢筋绑扎方法开展一定程度的改进, 全面 提高整体施工效率, 简化作业流程, 不会因为天气因素造成影响, 一般情况下, 采用工厂化加工方法不宜受到气候所 
干扰，若在冬季施工，叠合板施工技术可大大提高施工速度，并强化结构施工质量。

\section{2 叠合板施工技术要点}

\section{1 叠合板制作}

在装配式施工进行前, 要对图纸进行优化设计, 工作人员需根据各种专业需要开展科学安排, 有效提高设计几何 度, 运用简化、统一的符号, 对各种需求进行准确表达。另外, 要对构件生产工艺深入研究, 在图纸设计完毕后, 生 产厂商要对模具组装方案进行合理设计, 测算模具侧模的垂直度与对应尺寸, 保证模具表面的清洁, 不可在钢筋上涂 刷隔离剂, 在进行钢筋施工过程中, 施工人员要按照设计图进行准确安装。混凝土浇筑过程中, 不可与预埋件接触。 科学放置相关构件, 保证存放地点的平整, 做好排水, 不让构件直接和地面接触, 根据构件的实际受力情况与刚度选 择合适的摆放方式, 一般情况下, 要采用叠合平放的方法。叠合板尺寸多样化, 数量众多, 实际施工过程中机电管道 设置错综复杂, 预留孔洞工程量大, 设计单位要根据实际情况深化设计 ${ }^{[1]}$ 。

\section{2 叠合板运输}

要制定合理的运输方案, 在运输过程中发生损坏会影响正常的施工进度, 对整体施工项目造成经济损失。因此, 在运输构件前要做出科学规划, 在运输前需对构件的各方面数据进行认真检查, 查看出厂合格标记。选择合适的运输 车辆, 通过平板拖车与卡车进行运输, 在车厢底面放置两个木方, 保证截面为 $100 \mathrm{~m}^{2}$, 另外, 还要在上面放上一个厚度 超过 $15 \mathrm{~mm}$ 的垫子, 根据实际尺寸进行设置, 在实际运输之前, 对沿途状况仔细检查, 设计最佳线路, 运输过程中保证 车辆的匀速行驶, 避免构件受到外力而产生形变, 防止产生掉角、裂纹等情况。

\section{3 叠合板吊装}

在起吊过程中, 要合理使用模数化吊装梁, 保证各个吊点间受力均匀, 在腹筋与格构梁交界位置设置吊点, 与板 块的距离是板长的五分之一, 匀速起吊保证叠合板起吊的稳定性。在锁链吊装过程中, 要合理使用闭合吊钩与专用锁 链, 可以很好分担受力, 锁链长度一般为 $4 \mathrm{~m}$, 在作业层上部 $300 \mathrm{~mm}$ 位置要略做停留, 根据实际位置进行方向调节, 再 开展定位。在吊装阶段, 要防止坚向钢筋与预留钢筋发生接触, 对叠合板来说, 要稳停慢放, 以免冲击力过大破坏板 面, 在纠正误差过程中, 要借助璞形小木块进行适当调整, 不可使用其他方法调节, 防止损坏板边, 楼板铺设结束后, 保证平整度, 以免下边缘不整齐, 避免出现空隙, 发现空隙时要迅速实行封堵处理, 适当调节支撑, 保证板面无裂缝。 吊装需严格遵守策划顺序开展, 防止现场施工杂乱无章, 拖延施工进度, 划分几个吊装区域, 各个区域优先吊装中间 板块, 各班组人员不变, 技术人员协助吊装人员对叠合板的就位复核尺寸。根据预先位置实行起吊, 不可任意将吊钩 固定在桁架钢筋上, 防止构件被损坏 ${ }^{[2]}$ 。

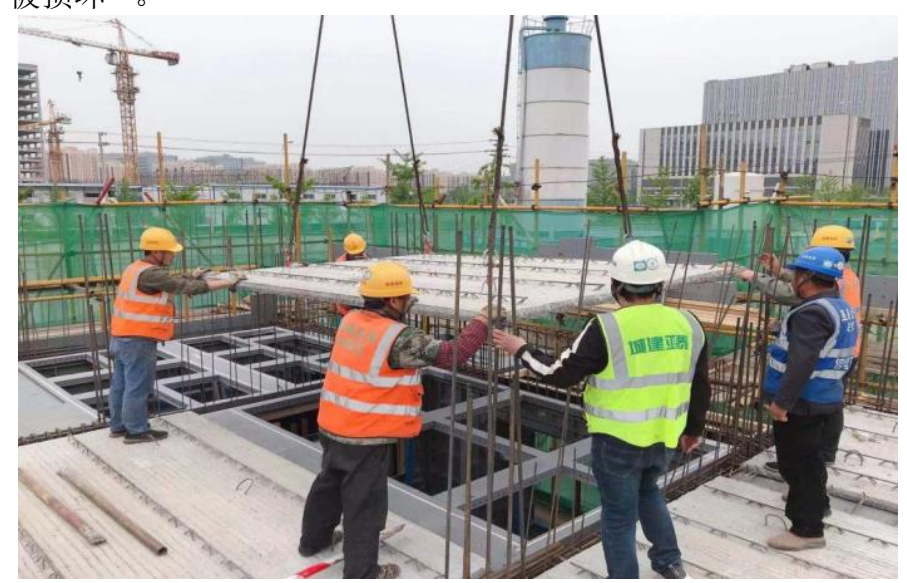

图 1 叠合板吊装施工图

\section{4 接缝技术}

装配式结构中的接缝通常指叠合板相互的接缝、叠合板和混凝土之间的接缝、阳台和外墙的接缝、板和梁的接缝等, 接缝会严重影响结构的受力情况。接缝之间包括压力、剪力与拉力, 接缝压力经过混凝土、灌浆料和坐浆材料直接传导, 拉力由钢筋、预埋件传递, 剪力由键槽、销栓、钢筋摩擦支撑, 在接缝在受压或受弯过程中, 剪力摩擦能够分担一部分 剪力, 叠合板接缝处运用的材料需高于后浇材料, 才可保证正常的受力, 若选择高强材料, 则无需进行承载力测算。 
各种装配式建筑的控制区域较为关键, 接缝需进行强连接, 确保不在接缝位置出现脆性破坏, 连接系数与连接构 件的承载力设计值相乘要小于接缝承载力设计值, 强连接系数受多种要素的影响, 要参考抗震等级、连接类型与连接 地区的重要性来确定。在非控制位置能够使用延性连接, 允许连接位置出现塑性变形, 但不会出现破坏, 保证接缝承 载力设计值高于设计内力, 确保接缝安全性, 一些接缝方法比较简单, 有助于叠合板的大规模施工。后浇层超过 $75 \mathrm{~mm}$, 钢筋配置率要达到规定要求, 接缝要能够承受一定的弯矩与剪力, 另外, 在整体式接缝中, 几块预制板经过接缝可根 据整体叠合双向板进行设计。侧接缝能够满足钢筋和混凝土的连续受力, 形成一个整体, 整体接缝通常运用后浇带的 方式, 后浇带的宽度可以确保钢筋在后浇带的针固空间, 确保后浇混凝土和预制板融为一体。经实践表明, 和整体现 浇板进行对比, 接缝位置的应变应力越集中, 裂缝宽度越大, 致使构件挠度超过整体现浇板, 接缝位置的受弯承载力 有所减小。在设计过程中, 若接缝处于关键位置, 要考虑其影响, 根据测算的内力和配筋结果予以调节, 适度提高两 个方向的纵向受力, 墙板水平接缝用座浆材料的强度等级需略高过连接构件的混凝土强度等级值。在符合使用标准的 基础上, 接缝材料要具备抗剪切、防水、防火等方面的能力, 板缝不可过宽, 应尽可能少使用密封胶, 降低施工成本, 板缝尽可能达到协调、美观、干净整洁。

叠合板的受力性能在整体双向板与单向板的范围内, 和楼板尺寸、预制板和后浇层的厚度比、钢筋数量等要素有 关。板缝接㖓边界是因为后浇与整体性不同, 拥有较好的传递剪力性能, 当缺乏有效依据时, 可根据单向板展开设计, 接缝钢筋根据构造要求确定, 主要为确保接缝位置不受到损坏, 避免裂缝产生 ${ }^{[3]}$ 。

当叠合板跨度较大, 或叠合面上外力、温度等发生变化, 截面上会出现较大的水平剪力, 通过设置抗剪构造钢筋 以提高水平的抗剪能力, 若不存在桁架钢筋, 抗剪钢筋可选用马镫形, 钢筋间距、直径与针固长度要符合叠合面抗剪 要求。整体式缝要同时规避最大受力处和最大弯矩截面, 接缝使用后浇带形式, 受力钢筋要运用安全的连接形式, 接 缝位置新旧混凝土之间使用粗粘面与键槽等构造方法时, 结构整体性能和现浇结构相似, 在设计阶段要使用和现浇结 构相似的方法分析结构, 按照相关规定调整测算结果。

\section{5 支撑体系设计}

要科学设置立杆支撑, 普遍使用木模板支撑与铝模板支撑两种方法, 立杆顶端要运用可调顶撑, 对支撑标高进行 适当调整, 在 U 托中放置主龙骨, 并科学设置次龙骨, 让距离保持在 $200 \mathrm{~mm}$, 次龙骨中间与四周放置模板条, 使用海绵 条对接缝处密封好, 放置出现漏浆情况。在设计铝模板阶段, 要保证叠合板支撑与标高调节能够正常进行。在这个阶段, 要保持立杆支撑间距小于 $18 \mathrm{~m}$, 若间隔太大, 需要增加立杆, 在安装前做好支设, 独立加工三角支撑架, 固定好支撑立杆。

\section{6 上层混凝土浇筑}

在叠合板施工过程中, 现浇混凝土厚度为 $7 \mathrm{~cm}$, 所以, 现浇结构上要尽可能防止预留预埋, 在这个阶段, 可在施工 楼层预埋螺栓, 在高层施工阶段, 运用附着式升降脚手架, 在项目建设阶段, 工作人员要确定好布料机的具体位置, 一般需在现浇结构位置安放布料机, 若楼层中不存在现浇结构板, 工作人员在实际设计时可把布料机底座作为现浇结 构, 在浇筑混凝土过程中, 要控制好墙根板面高度, 以免在下层施工阶段, 叠合板标高不符合施工标准, 导致接缝不 严出现漏浆情况。

\section{3 现场施工质量控制}

要做好成品保护工作, 在把叠合板运输到施工现场后, 要对场地进行合理规划, 安排专门人员进行看管, 在这个 过程中, 严格控制堆放高度, 保证不超出三层。若碰到恶劣天气, 要将彩条覆盖到材料上, 有关工作人员要保证材料 不会堆放超过三天。另外, 不可忽视对标高的控制, 在安装结束后, 测量人员要合理测量标高, 若出现不平整的情况, 要及时予以调整, 保证误差在 $5 \mathrm{~mm}$ 以内, 若平整度没有达到要求, 不可进行后续浇筑工作。要严格遵守施工计划开展 绑扎作业, 另外, 在实际施工阶段, 不可弯折构件, 从下至上进行绑扎作业, 防止因为钢筋疲劳减小强度与刚度。

\section{4 结论}

运用好叠合板施工技术, 可以有效解决先浇筑混凝土施工技术中的问题, 经过技术人员的深入探究后可以发现, 此方法拥有较强的可行性, 装配式建筑模式有较大优势, 要不断优化施工过程中的每个环节, 提升施工质量, 使建设 企业获得更高的经济收益。

\section{[参考文献]}

[1]王琴. 预制装配式建筑结构设计研究 [J]. 建筑与文化, 2021 (4): 26-29.

[2] 赵智慧. 装配式建筑结构设计要点与应用分析 $[\mathrm{J}]$. 建筑经济, 2021, 42 (4) : 159-160.

[3] 马倩. 装配式建筑结构设计要点分析 [J]. 居舍, 2021 (8): 84-85.

作者简介: 李建萌 (1993-), 男, 河北唐山市丰南区人, 汉族, 大学本科学历, 助理工程师。 